\title{
Exigência nutricional de lisina digestível para poedeiras leves no segundo ciclo de produção
}

\author{
Marlene Schmidt ${ }^{*}$, Paulo Cezar Gomes ${ }^{2}$, Horacio Santiago Rostagno ${ }^{2}$, Luiz Fernando \\ Teixeira Albino ${ }^{2}$, Ricardo Vianna Nunes ${ }^{3}$, Arele Arlindo Calderano ${ }^{4}$
}

\author{
1 Programa de Pós-graduação em Zootecnia - UFV. \\ 2 Departamento de Zootecnia, UFV - CEP: 36571-000 - Viçosa, MG. \\ ${ }^{3}$ Departamento de Zootecnia, UNIOESTE - CEP: 85960-000 - Marechal Cândido Rondon - PR. \\ ${ }^{4}$ Curso de Graduação em Zootecnia, UNIOESTE - CEP: 85960-000 - Marechal Cândido Rondon - PR.
}

RESUMO - Com o objetivo de determinar a exigência nutricional de lisina digestível para poedeiras de segundo ciclo de produção, no período de 79 a 95 semanas de idade, foi conduzido um experimento utilizando 180 poedeiras Lohmann LSL leves, distribuídas em cinco níveis de lisina digestível $(0,555 ; 0,605 ; 0,655 ; 0,705$; e $0,755 \%)$, seis repetições e seis aves por unidade experimental. Foi observado efeito quadrático dos níveis de lisina sobre consumo de ração, ganho de peso, conversão alimentar/massa de ovos, peso e massa de ovos. Para as características consumo de lisina, conversão alimentar/dúzia e taxa de postura, foi observado efeito linear positivo dos níveis de lisina. A porcentagem dos componentes dos ovos e a qualidade interna não foram influenciadas pelos tratamentos, com exceção da porcentagem de casca e do índice de gema, que apresentaram efeito linear negativo. Embora tenha sido obtido efeito quadrático para massa de ovos e conversão alimentar/massa de ovos, estas características não foram utilizadas para determinação da exigência de lisina digestível para as aves leves, visto que não atenderiam à exigência de lisina encontrada para os demais parâmetros. Deste modo, a exigência estimada de lisina digestível para as poedeiras leves, mediante efeito linear, foi maior ou igual a $0,755 \%$, o que corresponde a um consumo de pelo menos $885 \mathrm{mg}$ de lisina digestível/ave/dia.

Palavras-chave: aminoácido, qualidade de ovos, produção de ovos

\section{Nutritional requirement of digestible lysine to white-egg laying hens on the second cycle of production}

\begin{abstract}
The nutritional requirement of digestible lysine was determined in 180 Lohmann LSL white-egg laying hens raised from 79 to 95 weeks of age. The birds were allotted to five levels $(0.555 ; 0.605 ; 0.655 ; 0.705$ and $0.755 \%$ ) of digestible lysine, six replicates and six birds per experimental unit. Quadratic effect of digestible lysine levels on feed intake, average weight gain, feed conversion/egg mass, the egg weight and the egg mass was observed. For the characteristics digestible lysine intake, feed conversion/dozen eggs and egg production a positive linear effect of digestible lysine levels was observed. The percentage of the components of the eggs and the internal quality were not affected by the digestible lysine levels, except for percentages of shell and yolk index, which showed linear negative effect. Although it was observed quadratic effect on egg mass and feed conversion/egg mass, these characteristics were not used to determine digestible lysine requirements for the white-egg birds, since these traits did not meet the requirement of digestible lysine observed for the other traits. Thus, the estimated requirement of digestible lysine for the white-egg laying hens, using linear effect was higher or equal to $0.755 \%$, corresponding to an intake of at least $885 \mathrm{mg}$ of digestible lysine/bird/day.
\end{abstract}

Key Words: amino acids, egg quality, egg production

\section{Introdução}

A proteína é considerada um dos principais nutrientes presentes nas dietas de aves, pois é importante no desempenho dos animais, apesar do elevado custo.
Segundo Dale (1994), a proteína dietética influencia o desempenho dos animais e sua eficiência de utilização é dependente da quantidade, da composição e da digestibilidade de seus aminoácidos, os quais são exigidos em níveis específicos pelas aves. 
Os avanços no conhecimento do metabolismo protéico e o surgimento de novos aminoácidos sintéticos, com produção em grande escala comercial e a preços compatíveis , têm permitido aos nutricionistas formulações de dietas mais próximas da exigência animal, resultando em melhor aproveitamento da proteína dietética, com menores custos e produção de resíduos menos nocivos ao meio ambiente. Outra grande vantagem do uso de aminoácidos sintéticos é a possibilidade de se estabelecer uma relação ideal entre todos os aminoácidos na dieta, por intermédio do conceito de proteína ideal, tendo como resultado imediato a redução dos níveis protéicos da ração. Segundo Parsons \& Baker (1994), quando se trabalha com base na proteína ideal, tem-se uma mistura adequada de aminoácidos, de forma a atender, sem excesso ou deficiência, a exigência de aminoácidos para mantença, crescimento e produção.

A dieta deve garantir os aminoácidos essenciais em um nível adequado de proteína bruta (PB) para assegurar um satisfatório pool de nitrogênio para síntese de aminoácidos (NRC, 1994). No entanto, em condições brasileiras de temperaturas elevadas, deve-se sempre aumentar a quantidade de aminoácidos sintéticos com o mínimo incremento de proteína para não ocorrer aumento na produção de calor endógeno gerado pela digestão protéica (Garcia, 2004).

Andrade et al. (2003) conduziram um experimento utilizando diferentes níveis de proteína com a suplementação de aminoácidos e concluíram que, de forma geral, os parâmetros de qualidade de ovos não foram afetados pela redução protéica, além de ser possível obter o mesmo desempenho e produtividade de poedeiras com redução de custos das dietas, por meio da diminuição da proteína dietética e suplementação de aminoácidos. Narváez-Solarte et al. (2005) citam que, em aves de postura de segundo ciclo de produção, $14 \%$ de proteína na ração é suficiente para adequado desempenho, desde que mantidos a quantidade de aminoácidos essenciais e o balanço aminoacídico.

Rostagno et al. (2000) recomendam 0,702\% de lisina digestível para poedeiras leves em produção e Rostagno et al. (2005) sugerem $0,727 \%$ de lisina digestível para linhagem leve.

Jardim Filho et al. (2004b), trabalhando com níveis de 0,600 a $0,900 \%$ de lisina digestível, determinaram, em função do índice de conversão, $0,900 \%$ de lisina digestível na dieta de poedeiras Hy-Line W-36 de 28 a 44 semanas. Magalhães Araújo et al. (2005) sugerem, em função da conversão por massa de ovos produzidos, $0,720 \%$ de lisina digestível para poedeiras leves durante o pico de postura.

Pesquisas sobre níveis nutricionais de lisina específicos para poedeiras comerciais no segundo ciclo de produção são escassas. As recomendações do NRC (1994) não fazem referência a poedeiras de $2 \underline{\mathrm{O}}$ ciclo e a maioria dos manuais de linhagens também é omissa.

Em geral, adotam-se recomendações preconizadas para o final do primeiro ciclo de postura, com tendência geral de reduzir os níveis de todos os nutrientes, excetuando-se o cálcio. Isto pode ser interessante do ponto de vista de custo de produção, contudo, deve-se lembrar dos excelentes picos de produção pós-muda, modificando-se este procedimento (Oliveira, 1993).

Assim, o objetivo neste trabalho foi estabelecer a exigência de lisina digestível para poedeiras comerciais leves de segundo ciclo de produção, no período de 79 a 95 semanas de idade.

\section{Material e Métodos}

Foram utilizadas 180 poedeiras leves da linhagem comercial Lohmann LSL, distribuídas em cinco tratamentos, seis repetições e seis aves por unidade experimental.

Nas fases de cria, recria e produção, as aves foram manejadas conforme descrito no respectivo manual de linhagem, porém seguindo-se as recomendações de Rostagno et al. (2000), na elaboração das dietas. Na fase de produção, as aves foram alojadas aos pares em gaiolas $(25 \times 40 \times 45 \mathrm{~cm})$ dispostas em um galpão de postura $(60 \times 9 \mathrm{~m})$ fechado com tela nas laterias e coberto com telha de barro. As aves foram submetidas à muda forçada com 72 semanas, quando a postura caiu para $75 \%$, utilizando-se a metodologia adaptada de Cotta (2002). Após o período de jejum, as aves receberam ração para frangas, seguindo-se as recomendações de Rostagno et al. (2000); somente quando atingiram $50 \%$ de postura, o que correspondeu a uma idade de 79 semanas, as aves receberam as dietas experimentais.

Para determinação da exigência em lisina digestível, foram formuladas rações isoprotéicas, variando em cinco níveis de suplementação de lisina digestível. Os níveis foram obtidos a partir de uma dieta basal (Tabela 1) deficiente em lisina $(0,555 \%)$, suplementada com 0,$00 ; 0,066$; 0,132; 0,198; e 0,263\% de L-lisina $\mathrm{HCl}(78 \%)$, de forma a proporcionar 0,$555 ; 0,605 ; 0,655 ; 0,705 ;$ e $0,755 \%$ de lisina digestível nas dietas. Para cada nível de suplementação, foi mantida a relação dos aminoácidos essenciais em relação à lisina. As suplementações com L-Lis $\mathrm{HCl}$ (78\%) foram feitas em substituição ao aminoácido não essencial L-glutâmico. Os demais nutrientes contidos nas rações, exceto $\mathrm{PB}$, atenderam as recomendações preconizadas por Rostagno et al. (2000).

A partir da $79^{a}$ semana de idade, as poedeiras foram submetidas aos tratamentos, iniciando-se o período expe- 
rimental, que teve duração de 16 semanas, subdivididas em quatro períodos de 28 dias cada. As rações foram fornecidas diariamente em dois horários, às 7 e 17 h, garantido às aves consumo de alimento e água à vontade durante todo o período experimental.

As características avaliadas a cada período de 28 dias foram: consumo de ração, consumo de lisina (mg/ave/dia), conversão alimentar/dúzia de ovos, conversão alimentar/ massa de ovos, taxa de postura, peso de ovos, massa de ovos, porcentagem dos componentes dos ovos (casca, albúmen e gema) e qualidade interna dos ovos (unidade
Haugh, índice de gema e índice de albúmen). A variação de peso (ganho ou perda) foi avaliada somente no final do período experimental.

A coleta de ovos foi realizada diariamente e o cálculo da taxa de postura baseou-se no número de ovos/ave/dia. Os ovos foram pesados nos quatro últimos dias de cada período experimental para determinação do peso e da massa de ovos, esta última obtida por meio do produto do número de ovos produzidos em cada período pelo peso médio dos ovos.

Para determinação da porcentagem dos componentes dos ovos e da qualidade interna, foram coletados 4 ovos/

Tabela 1 - Composições em ingredientes e nutricional calculada das dietas experimentais

\begin{tabular}{|c|c|c|c|c|c|}
\hline \multirow[b]{2}{*}{ Ingrediente } & \multicolumn{5}{|c|}{ Nível de lisina digestível (\%) } \\
\hline & 0,555 & 0,605 & 0,655 & 0,705 & 0,755 \\
\hline Milho & 46,770 & 46,770 & 46,770 & 46,770 & 46,770 \\
\hline Sorgo & 23,180 & 23,180 & 23,180 & 23,180 & 23,180 \\
\hline Farelo soja & 16,020 & 16,020 & 16,020 & 16,020 & 16,020 \\
\hline Glúten milho & 1,466 & 1,466 & 1,466 & 1,466 & 1,466 \\
\hline Óleo de soja & 0,217 & 0,217 & 0,217 & 0,217 & 0,217 \\
\hline Fosfato bicálcico & 1,350 & 1,350 & 1,350 & 1,350 & 1,350 \\
\hline Calcário & 8,875 & 8,875 & 8,875 & 8,875 & 8,875 \\
\hline Cloreto colina & 0,020 & 0,020 & 0,020 & 0,020 & 0,020 \\
\hline Sal & 0,497 & 0,497 & 0,497 & 0,497 & 0,497 \\
\hline Suplemento vitamínico ${ }^{1}$ & 0,100 & 0,100 & 0,100 & 0,100 & 0,100 \\
\hline Suplemento mineral ${ }^{2}$ & 0,050 & 0,050 & 0,050 & 0,050 & 0,050 \\
\hline BHT $^{3}$ & 0,010 & 0,010 & 0,010 & 0,010 & 0,010 \\
\hline Carbonato de potássio & 0,059 & 0,059 & 0,059 & 0,059 & 0,059 \\
\hline Amido & 0,413 & 0,444 & 0,481 & 0,534 & 0,610 \\
\hline L-glutâmico & 0,904 & 0,756 & 0,588 & 0,339 & 0,010 \\
\hline L-lisina.HCL & 0 & 0,066 & 0,132 & 0,198 & 0,263 \\
\hline DL-metionina & 0,069 & 0,115 & 0,161 & 0,207 & 0,253 \\
\hline L-treonina & 0 & 0 & 0 & 0,010 & 0,048 \\
\hline L-triptofano & 0 & 0,005 & 0,018 & 0,030 & 0,043 \\
\hline L-isoleucina & 0 & 0 & 0,006 & 0,050 & 0,095 \\
\hline L-valina & 0 & 0 & 0 & 0,018 & 0,064 \\
\hline Total & 100 & 100 & 100 & 100 & 100 \\
\hline \multicolumn{6}{|c|}{ Composição nutricional calculada } \\
\hline Proteína bruta (\%) & 14,25 & 14,25 & 14,25 & 14,25 & 14,25 \\
\hline EM (kcal/kg) & 2800 & 2800 & 2802 & 2806 & 2810 \\
\hline $\mathrm{Ca}(\%)$ & 3,818 & 3,818 & 3,818 & 3,818 & 3,818 \\
\hline P disponível (\%) & 0,341 & 0,341 & 0,341 & 0,341 & 0,341 \\
\hline $\mathrm{Na}(\%)$ & 0,227 & 0,227 & 0,227 & 0,227 & 0,227 \\
\hline $\mathrm{K}(\%)$ & 0,545 & 0,545 & 0,545 & 0,545 & 0,545 \\
\hline Lisina digestível (\%) & 0,555 & 0,605 & 0,655 & 0,705 & 0,755 \\
\hline Metionina digestível (\%) & 0,289 & 0,334 & 0,379 & 0,424 & 0,469 \\
\hline Met + cis digestível $(\%)$ & 0,498 & 0,543 & 0,588 & 0,633 & 0,678 \\
\hline Treonina digestível (\%) & 0,471 & 0,471 & 0,471 & 0,480 & 0,513 \\
\hline Triptofano digestível (\%) & 0,141 & 0,146 & 0,158 & 0,169 & 0,181 \\
\hline Valina digestível (\%) & 0,609 & 0,609 & 0,609 & 0,627 & 0,672 \\
\hline Arginina digestível (\%) & 0,845 & 0,845 & 0,845 & 0,845 & 0,845 \\
\hline Leucina digestível (\%) & 1,408 & 1,408 & 1,408 & 1,408 & 1,408 \\
\hline Isoleucina digestível (\%) & 0,550 & 0,550 & 0,556 & 0,598 & 0,642 \\
\hline Histidina digestível (\%) & 0,348 & 0,348 & 0,348 & 0,348 & 0,348 \\
\hline Fenilalanina digestível (\%) & 0,672 & 0,672 & 0,672 & 0,672 & 0,672 \\
\hline
\end{tabular}

1 Vitamina matrizes - Composição/kg: vit. A 12.000 .000 U.I., vit $D_{3} 3.600 .000$ U.I., vit. E 3.500 U.I., vit $B_{1} 2.500$ mg, vit $B_{2} 8.000$ mg, vit $B_{6} 3.000$ mg, ác. pantotênico (Panthotenic acid) $12.000 \mathrm{mg}$, biotina, $200 \mathrm{mg}$, vit. K $3.000 \mathrm{mg}$, ác. fólico $3.500 \mathrm{mg}$, ác. nicotínico $40.000 \mathrm{mg}$, vit. $\mathrm{B}_{12} 20.000 \mathrm{mcg}$, Se $130 \mathrm{mg}$, veículo q.s.p. $1.000 \mathrm{~g}$.

${ }^{2}$ Mineral Aves - Composição/kg : Mn -160g, Fe -100g, Zn -100g, Cu - 20g, Co -2g, I-2g, excipiente q.s.p. - 1000 g.

${ }^{3}$ Butil-hidróxi-tolueno (antioxidante). 
unidade experimental nos três últimos dias de cada período, dois para determinação da porcentagem de casca, albúmen e gema e dois para determinação da unidade Haugh, índice de gema e de albúmen (Haugh, 1937).

As análises estatísticas dos parâmetros avaliados foram realizadas de acordo com o programa SAEG (UFV, 1997), utilizando-se os modelos de regressão linear e quadrático.

\section{Resultados e Discussão}

Foi observado efeito quadrático dos níveis de lisina $(\mathrm{P}<0,01)$ sobre o consumo de ração ea conversão alimentar por massa de ovos $(\mathrm{P}<0,05)$. Para o consumo de lisina e a conversão alimentar por dúzia de ovos, obteve-se efeito linear dos níveis de lisina $(\mathrm{P}<0,01)$. As exigências de lisina para poedeiras leves foram estimadas em 0,701 e $0,727 \%$, o que corresponde ao consumo de 810 e $846 \mathrm{mg}$ de lisina/ave/ dia para consumo de ração e conversão alimentar por massa de ovos, respectivamente (Tabela 2).

Carvalho et al. (2004), trabalhando com poedeiras leves no período final de postura (44 a 55 semanas) submetidas a estresse térmico e alimentadas com dietas contendo níveis crescentes de lisina total $(0,541$ a $0,861 \%)$, observaram efeito linear $(\mathrm{P}<0,05)$ para consumo de ração e conversão alimentar $(\mathrm{g} / \mathrm{g})$, contrariando os resultados obtidos neste trabalho. Esses autores concluíram que a exigência de lisina total para aves submetidas ao estresse térmico é igual ou superior a $0,861 \%$, correspondendo a um consumo médio equivalente a $786 \mathrm{mg}$ de lisina total/ave/dia.

Para consumo de ração e conversão alimentar por dúzia de ovos, os resultados encontrados assemelham-se aos observados por Jardim Filho et al. (2004b). Esses autores, avaliando níveis de 0,6 a $0,9 \%$ de lisina digestível em dietas de poedeiras leves, observaram efeito linear $(\mathrm{P}<0,05)$ para conversão alimentar por dúzia de ovos $(\mathrm{kg} / \mathrm{dz})$ e efeito quadrático $(\mathrm{P}<0,05)$ para consumo de ração às 28 semanas de idade, sugerindo $0,900 \%$ de lisina digestível para melhor resultado dos índices de conversão.

Foi observado efeito significativo dos níveis de lisina na ração para taxa de postura, peso e massa de ovos. Para a taxa de postura foi observado efeito linear $(\mathrm{P}<0,01)$ dos níveis de lisina e para peso e massa de ovos, resposta quadrática $(\mathrm{P}<0,01)$ (Tabela 3$)$.

Sá et al. (2007) observaram efeito quadrático $(\mathrm{P}<0,05)$ dos níveis de lisina digestível dietética na taxa de postura em poedeiras leves e estimaram a exigência de $0,706 \%$, o que corresponde ao consumo de $861 \mathrm{mg}$ de lisina digestível/ ave/dia.

Jardim Filho et al. (2004a), trabalhando com níveis de lisina digestível $(0,600$ a $0,900 \%)$, observaram que o peso de ovo foi influenciado de forma negativa pelo aumento de lisina na dieta de poedeiras comerciais Lohmann LSL com 28 semanas de idade. Segundo os autores, nesta idade é comum a produção de ovos pequenos. Segundo Gourlart (1997), o excesso de aminoácidos no sangue tende a diminuir o consumo de ração e, conseqüentemente, afeta o tamanho do ovo produzido. Por outro lado, Novak et al. (2000) observaram melhores resultados de peso do ovo, ao utilizarem níveis de $0,900 \%$ de lisina na ração.

Os resultados da taxa de postura são condizentes com os de Carvalho et al. (2004), que utilizaram níveis de lisina variando de 0,541 a $0,861 \%$ para poedeiras no final de postura (44 a 55 semanas), observando efeito linear $(\mathrm{P}<0,05)$ sobre a taxa de postura. Por outro lado, para peso de ovos não observaram efeito $(\mathrm{P}>0,05)$ e para massa de ovos obtiveram efeito linear $(\mathrm{P}<0,05)$ dos níveis de lisina na ração. Jardim Filho et al. (2004b) não observaram efeito dos níveis de lisina na dieta sobre a taxa de postura de poedeiras Hy-Line W 36, no período de 28 a 44 semanas de idade.

As exigências de lisina estimadas para peso e massa de ovos foram de 0,685 e $0,721 \%$, o que corresponde, respec-

Tabela 2 - Efeito dos diferentes níveis de lisina digestível sobre consumo de ração, consumo de lisina, conversão alimentar por dúzia de ovos (CADZ) e conversão alimentar por massa de ovos (CAMO), no período de 79 a 95 semanas de idade

\begin{tabular}{lcccc}
\hline Lisina digestível (\%) & Consumo ração (g/ave/dia) ${ }^{1 ; 3^{* *}}$ & Consumo lisina (mg/ave/dia) $)^{* *}$ & CADZ (kg/dúzia) $)^{2 ; * *}$ & CAMO (g/g) $)^{1 ; 5^{*}}$ \\
\hline 0,555 & 106,25 & 589,67 & 1,80 & 2,39 \\
0,605 & 113,94 & 689,34 & 1,79 & 2,23 \\
0,655 & 115,63 & 757,39 & 1,70 & 2,11 \\
0,705 & 115,66 & 815,39 & 1,63 & 2,06 \\
0,755 & 116,07 & 876,35 & 1,64 & 2,07 \\
\hline CV $(\%)$ & 1,96 & 1,86 & 5,69 & 5,76 \\
\hline
\end{tabular}

${ }^{1}$ Efeito quadrático; ${ }^{2}$ Efeito linear; ${ }^{* *}(P<0,01) ;{ }^{*}(P<0,05)$.

$3 \hat{\mathrm{Y}}=-111,026+649,939 \mathrm{x}-463,507 \mathrm{x}^{2}\left(\mathrm{R}^{2}=0,94\right)$.

$4 \hat{\mathrm{Y}}=2,33715-0,953333 x\left(R^{2}=0,89\right)$.

$5 \hat{Y}=8,09600-16,6162 x+11,4321 x^{2} \quad\left(R^{2}=0,99\right)$. 
Tabela 3 - Efeito dos diferentes níveis lisina digestível sobre taxa de postura, peso de ovos e massa de ovos, no período de 79 a 95 semanas de idade

\begin{tabular}{lccc}
\hline Lisina digestível $(\%)$ & Taxa de postura $(\%)^{1,3}$ & Peso dos ovos $(\mathrm{g})^{2,4}$ & Massa de ovos (g/ave/dia) $)^{2,5}$ \\
\hline 0,555 & 71,15 & 62,84 & 44,73 \\
0,605 & 77,42 & 66,46 & 51,43 \\
0,655 & 82,45 & 66,57 & 54,80 \\
0,705 & 83,27 & 67,53 & 56,16 \\
0,755 & 85,27 & 66,17 & 56,43 \\
\hline CV $(\%)$ & 5,78 & 1,06 & 5,95 \\
\hline
\end{tabular}

${ }^{1}$ Efeito linear $(P<0,01) ;{ }^{2}$ Efeito quadrático $(P<0,01)$.

$3 \hat{\mathrm{Y}}=35,2777+68,1438 x \quad\left(R^{2}=0,90\right)$.

$4 \hat{\mathrm{Y}}=-54,6159+356,552 \mathrm{x}-260,379 \mathrm{x}^{2}\left(\mathrm{R}^{2}=0,93\right)$.

$5 \hat{Y}=-164,439+613,261 x-425,179 x^{2} \quad\left(R^{2}=0,99\right)$.

tivamente, ao consumo de 788 e 838 mg/ave/dia, para poedeiras leves.

Schutte \& Swink (1998) conduziram um experimento para determinar o requerimento de lisina para poedeiras leves. A exigência de lisina total com base nos dados de conversão alimentar e massa de ovo de $57 \mathrm{~g} / \mathrm{ave} / \mathrm{dia}$ foi estimado em $900 \mathrm{mg} / \mathrm{ave} / \mathrm{dia}$. Segundo os autores, na prática, os níveis de lisina utilizados são mais baixos que os citados acima, mas o requerimento de lisina foi determinado para maximizar a eficiência de utilização da ração pelas aves. Por outro lado, a exigência encontrada neste trabalho, para melhor resultado de massa de ovos de $56,7 \mathrm{~g} / \mathrm{ave} / \mathrm{dia}$, foi de $838 \mathrm{mg}$ de lisina digestível/ave/dia.

Faria et al. (2003), em dois experimentos, reavaliaram a exigência de lisina total em uma dieta suplementada com todos os aminoácidos, deixando a lisina como limitante, para poedeiras comerciais. De acordo com a regressão broken-line, a exigência diária de lisina foi de 633,1 e 642,9 mg/ave/dia no experimento I e de 606,6 mg/ave/dia, no experimento II, para produção e massa de ovos, respectivamente, valores inferiores aos deste trabalho.

Os níveis de lisina não influenciaram $(\mathrm{P}>0,05)$ a unidade Haugh, o índice de gema e índice de albúmem (Tabela 4). Jardim Filho et al. (2004a) também não observaram efeito dos níveis de lisina $(0,600$ a 0,900\%) sobre a unidade Haugh e o índice de gema de poedeiras comerciais Lohmann LSL (28 a 44 semanas de idade). De forma semelhante, Sá et al. (2007), trabalhando com poedeiras leves e avaliando as mesmas características, não observaram efeito dos níveis de lisina sobre estes parâmetros. Prochasca et al. (1996), avaliando a influência da ingestão de três níveis de lisina $(677 ; 1.154$ e $1.613 \mathrm{mg} / \mathrm{ave} / \mathrm{dia}$ ) sobre os componentes dos ovos (sólidos do albúmen, sólidos de gema, proteína do albúmen e proteína da gema) de poedeiras de 42 a 64 semanas de idade, detectaram efeito significativo nas características avaliadas, sendo que o maior nível de ingestão de lisina proporcionou maior resposta destes componentes.

As porcentagens de casca, albúmen e gema não foram influenciadas $(\mathrm{P}>0,05)$ pelos níveis de lisina na ração para ambas as linhagens, com exceção da porcentagem de casca, para a qual foi observado efeito linear negativo $(\mathrm{P}<0,01)$ (Tabela 5). Estes resultados estão de acordo com Rombola et al. (2004), que, ao avaliarem diferentes níveis de proteína e dois níveis de lisina $(0,850$ e $1,000 \%)$ em dietas de poedeiras leves (49 a 56 semanas de idade), não observaram efeito dos níveis de lisina sobre a porcentagem de gema e de albúmen e concluíram que, de modo geral, a qualidade interna dos ovos é alterada pelos níveis de proteína ou de lisina na dieta. Por outro lado, Novak et al. (2000) obtiveram melhores resultados de porcentagem de albúmen e de gema quando trabalharam com $0,900 \%$ de lisina na ração de poedeiras comerciais.

A variação de peso corporal apresentou efeito quadrático $(\mathrm{P}<0,05)$. Os níveis deficientes de lisina na dieta $(0,555$ e $0,605 \%)$ promoveram maior perda de peso na linhagem leve, que reduziu com o aumento de lisina na dieta (Tabela 6). A maior perda de peso, observada nos níveis nutricionais de 0,555 e $0,605 \%$ de lisina digestível, pode ser explicada pelo fato de as aves consumirem

Tabela 4 - Efeito dos níveis de lisina digestível sobre a unidade Haugh, o índice de gema e índice de albúmem, no período de 79 a 95 semanas de idade

\begin{tabular}{lccc}
\hline Lisina digestível (\%) & Unidade Haugh & $\begin{array}{c}\text { Índice de } \\
\text { gema }\end{array}$ & $\begin{array}{c}\text { Índice de } \\
\text { albúmen }\end{array}$ \\
\hline 0,555 & 90,69 & 0,488 & 0,117 \\
0,605 & 91,35 & 0,487 & 0,119 \\
0,655 & 91,42 & 0,489 & 0,119 \\
0,705 & 92,52 & 0,502 & 0,119 \\
0,755 & 89,20 & 0,490 & 0,118 \\
\hline CV $(\%)$ & 2,97 & 4,62 & 5,57 \\
\hline
\end{tabular}


Tabela 5 - Efeito dos níveis de lisina digestível sobre a porcentagem de casca, albúmen e gema no período de 79 a 95 semanas de idade

\begin{tabular}{lccc}
\hline Lisina digestível $(\%)$ & $\%$ casca $^{1,2}$ & $\%$ albúmen & $\%$ gema \\
\hline 0,555 & 9,99 & 64,31 & 25,70 \\
0,605 & 9,72 & 64,63 & 25,66 \\
0,655 & 9,78 & 64,02 & 26,20 \\
0,705 & 9,78 & 64,50 & 25,72 \\
0,755 & 9,37 & 64,51 & 26,11 \\
\hline CV $(\%)$ & 2,06 & 0,89 & 2,13 \\
\hline
\end{tabular}

${ }^{1}$ Efeito linear $(\mathrm{P}<0,01)$.

$2 \hat{\mathrm{Y}}=11,2770-2,36550 \times\left(R^{2}=0,69\right)$.

Tabela 6 - Efeito dos níveis de lisina digestível sobre a variação de peso corporal no período de 79 a 95 semanas de idade

\begin{tabular}{lccc}
\hline $\begin{array}{l}\text { Lisina digestível } \\
(\%)\end{array}$ & $\begin{array}{c}\text { Peso inicial } \\
\text { (g/ave) }\end{array}$ & $\begin{array}{c}\text { Peso final }^{1} \\
\text { (g/ave) }\end{array}$ & $\begin{array}{c}\text { Variação peso } \\
\text { (g/ave) }\end{array}$ \\
\hline 0,555 & 1.558 & 1.487 & -71 \\
0,605 & 1.565 & 1.482 & -83 \\
0,655 & 1.563 & 1.545 & -18 \\
0,705 & 1.558 & 1.563 & -5 \\
0,755 & 1.558 & 1.573 & -15 \\
\hline $\mathrm{CV}(\%)$ & 0,61 & 4,42 & $-38,24$ \\
\hline
\end{tabular}

${ }^{1}$ Efeito linear $(P<0,05) ;{ }^{2}$ Efeito quadrático $(P<0,05)$.

$3 \hat{Y}=-868,82+2176,6 x-1371,4 x^{2} \quad\left(R^{2}=0,74\right)$.

menores quantidades de rações, contribuindo para baixo consumo de lisina.

Os valores de exigência de lisina digestível considerando as principais características estudadas variaram de $0,685 \mathrm{a} \geq 0,755 \%$ para as poedeiras leves (Tabela 7).

Embora tenha sido obtido efeito quadrático para massa de ovos e conversão alimentar por massa de ovos, não foram utilizados estes parâmetros para determinar a exigência de lisina digestível, pois não atenderiam a exigência de lisina encontrada para os demais parâmetros, que também apresentam grande importância econômica (taxa de postura e conversão alimentar por dúzia de ovos produzidos). Deste modo, a exigência estimada de lisina digestível para as poedeiras leves foi de $\geq 0,755 \%$, o que corresponde ao consumo de pelo menos $885 \mathrm{mg}$ de lisina digestível/ave/dia.

O valor de exigência de lisina estimado para as poedeiras leves está próximo ao sugerido por Schutte \& Swink (1998), que determinaram o requerimento de lisina para poedeiras leves em $900 \mathrm{mg} / \mathrm{ave} / \mathrm{dia}$ e muito próximo ao valor sugerido por Sá et al. (2007), que recomendaram 0,732\%, equivalendo ao consumo de $893 \mathrm{mg}$ de lisina digestível/ave/dia. Por outro lado, o requerimento de lisina digestível determinado neste experimento foi superior aos estabelecidos por Rostagno et al. (2000, 2005).
Tabela 7 - Exigências nutricionais de lisina digestível e consumo de lisina/ave/dia para taxa de postura, massa de ovos, peso de ovos, conversão alimentar por dúzia de ovos (CADZ) e conversão alimentar por massa de ovos (CAMO), no período de 79 a 95 semanas de idade

\begin{tabular}{lcc}
\hline Item & \% lisina digestível & mg lisina/ave/dia \\
\hline Taxa de postura (\%) & 0,755 & 885 \\
Massa de ovos(g/ave/dia) & 0,721 & 838 \\
Peso de ovos(g) & 0,685 & 788 \\
CADZ (kg ração/dúzia ovos) & 0,755 & 885 \\
CAMO (g ração/g massa ovos) & 0,727 & 846 \\
\hline
\end{tabular}

\section{Conclusões}

Recomenda-se o nível nutricional de pelo menos $0,755 \%$ de lisina digestível na dieta, o que corresponde a consumo diário de $885 \mathrm{mg}$ de lisina para poedeiras leves,noperíodo de 79 a 95 semanas de idade.

\section{Literatura Citada}

ANDRADE, L.; JARDIM FILHO, R.M.; STRINGHINI, J.H. et al. O uso de rações com diferentes níveis de proteínas suplementadas com aminoácidos na alimentação de poedeiras na fase inicial de produção. Revista Brasileira de Ciência Avícola. Suplemento 5, p.66, 2003

CARVALHO, D.C.O.; ALBINO, L.F.T.; ROSTAGNO, H.S. et al. Exigências nutricionais de lisina para poedeiras leves no período final de postura, submetidas a estresse térmico. Revista Brasileira de Ciência Avícola, Suplemento 6, p.102, 2004.

COTTA, T. Galinha: produção de ovos. Viçosa, MG: Aprenda Fácil, 2002. 280p.

DALE, N. Proteina ideal para pollos de engorde. Avicultura Profesional, v.11, n.3, p.104-107, 1994.

FARIA, D.E.; HARMS, R.H.; ANTAR, R.S. et al. Re-evaluation of the lysine requirement of the commercial laying hen in a cornsoybean meal diet. Journal Applied Poultry Research, v.23, p.161-174, 2003.

GARCIA, J.R.M. [2004]. Avanços na nutrição da poedeira moderna. Disponível em: <http://www.hylinedobrasil.com.br/ files/6_palestra-CBNA.pdf> Acesso em: 6/12/2005.

GOULART, C.C. Exigência nutricional de lisina para poedeiras leves e semipesadas. Viçosa, MG: Universidade Federal de Viçosa, 1997. 51p. Dissertação (Mestrado em Zootecnia) - Universidade Federal de Viçosa, 1997.

HAUGH, R.R. The Haugh unit for measuring egg quality. United States Egg Poultry Magazine, v.43, p.552-555, 1937.

JARDIM FILHO, R.M.; SANTOS, G.P.; STRINGHINI, J.H. et al. Características internas de ovos de poedeiras comerciais Lohmann alimentadas com níveis crescentes de lisina digestível. Revista Brasileira de Ciência Avícola, Suplemento 6, p.103, 2004a.

JARDIM FILHO, R.M.; SANTOS, G.P.; STRINGHINI, J.H. et al. Influência dos níveis de lisina sobre o desempenho de poedeiras comerciais - Hy-Line W36. Revista Brasileira de Ciência Avícola, Suplemento 6, p.103, 2004b.

MAGALHÃES ARAÚJO, D.; SILVA, J.H.V.; LIMA, M.R. et al. Níveis de lisina e arginina digestível para poedeiras no pico de postura. Revista Brasileira de Ciência Avícola, Suplemento 7, p.136, 2005. 
NARVÁEZ-SOLATE, W.V.; CONTRERAS, W.; PEZZATO, A.C. Efeito da proteína no desempenho de poedeiras leves no segundo ciclo de postura em condições climáticas tropicais. Revista Brasileira de Ciência Avícola, Suplemento 7, p.82, 2005.

NATIONAL RESEARCH COUNCIL - NRC. Nutrient requirements of poultry. 9.ed. Washington, D.C.: National Academy of Sciences, 1994. 155p.

NOVACK, C.; YAKOUT, H.; SCHEIDELER, S. Lysine levels in laying hens diets. The Nebraska Poultry Report, p.21-23, 2000.

OLIVEIRA, B.L. Alimentação de poedeiras leves após muda forçada. In: SIMPÓSIO LATINO AMERICANO DE NUTRIÇÃO DE AVES, 1993, Campinas. Campinas. Anais... Campinas: 1993. p.46-50.

PARSONS, C.M.; BAKER, D.H. The concept and use of ideal proteins in the feeding of non-ruminants. In: REUNIÃO ANUAL DA SOCIEDADE BRASILEIRA DE ZOOTECNIA, 31 ., 1994, Maringá. Anais... Maringá: Sociedade Brasileira de Zootecnia, 1994. p.20-128.

PROCHASKA, J.F.; CAREY, J.B.; SHAFER, D.J. The effect of L-lysine intake on egg component yield and composition in laying hens. Poultry Science, v.75, p.1268-1077, 1996.
ROMBOLA, L.G.; RIZZO, M.F.; FARIA, D.E. et al. Alimentação de poedeiras com diferentes níveis de proteína e lisina: desempenho e qualidade dos ovos. Revista Brasileira de Ciência Avícola, Suplemento 6, p.23, 2004.

ROSTAGNO, H.S.; ALBINO, L.F.T.; DONZELE, J.L. et al. Tabelas brasileiras para aves e suínos: composição de alimentos e exigências nutricionais. Viçosa, MG: Editora UFV, 2000. 141p.

ROSTAGNO, H.S.; ALBINO, L.F.T.; DONZELE, J.L. et al. Tabelas brasileiras para aves e suínos: composição de alimentos e exigências nutricionais. 2.ed. Viçosa, MG: Editora UFV, 2005. 186p.

SÁ, L.M.; GOMES, P.C.; ROSTAGNO, H.S. et al. Exigência nutricional de lisina digestível para galinhas poedeiras no período de 34 a 50 semanas de idade. Revista Brasileira de Zootecnia, v.36, p.1829-1836, 2007.

SCHUTTE, J.B.; SMINK, W. Requirement of the laying hen for apparent fecal digestible lysine. Poultry Science, v.77, n.5, p.697-701, 1998.

UNIVERSIDADE FEDERAL DE VIÇOSA - UFV. Central de Processamento de Dados - UFV/CPD. SAEG - Sistema para análise estatística e genética. Versão 8.0 Viçosa, MG: UFV, 1997. 54p. 